\title{
STRATEGI PEMASARAN KOMUNIKASI DIGITAL MARKETING PLATFORM (CASHBAC) UNTUK MENINGKATKAN DAYA BELI KONSUMEN
}

\author{
Katrina Katrin, Zon Vanel \\ Universitas Kristen Satya Wacana
}

\begin{abstract}
This research is focused on communication marketing strategies at PT. Global Pay Indonesia (Cashbac). The purpose of this research is to find out the marketing strategy of digital marketing platform (Cashbac) to increase consumer purchasing power. The main theory is Marketing Mix (4P). The object of this research is the communication marketing strategy by the sales team and the Marketing team at PT. Global Pay Indonesia (Cashbac). The research method used is qualitative with a case study approach. The results of this study are that the products offered by Cashbac are different from other products and give a benefit to user so user can attract consumers' purchasing power. The price offered is also varied, this is also one of the attractions of consumers to help determine their choices in buying using Cashbac. The target place is Jabodetabek because the target is credit card users, but Cashbac can already be used in several other cities because their nations wide merchants. Cashbac used Advertising, Sales promotions, publicity, Personal, Direct Marketing to promote their product.
\end{abstract}

\section{Keywords}

Strategy, communication

marketing strategy, marketing mix.

Correspondence Contact 602016005@student.uksw.edu

\section{PENDAHULUAN}

PT. Global Pay Indonesia (Cashbac) memiliki caranya untuk membuat masyarakat mengenal, mencoba, sampai setia menggunakan produk mereka. Ada dua bagian yang berperan penting dalam strategi komunikasi Cashbac, yaitu Sales dan Marketing. Tujuan dalam penelitian ini adalah untuk mengetahui strategi pemasaran komunikasi digital Marketing platform (Cashbac) untuk meningkatkan daya beli konsumen. Manfaat teoritis dari penelitian ini adalah agar dapat menjadi media pembelajaran mengenai promosi sebuah perusahaan. Manfaat praktis yaitu dapat menambah wawasan mengenai strategi pemasaran suatu perusahaan, serta dapat menjadi acuan untuk semakin meningkatkan strategi pemasaran Cashbac.

Penelitian dari Galih Kusnawan dan Purwohadi Wijoyo (2008) Jurusan Sosial Ekonomi Pertanian, Universitas Brawijaya, dengan judul "Pengaruh Strategi Bauran Pemasaran (Marketing Mix) Terhadap Efektivitas Volume Penjualan Sayuran Hidroponik". Dengan hasil analisis menunjukan bahwa volume penjualan sayuran hidroponik mengalami kenaikan untuk tiap tahunnya. Berdasarkan analisis regresi berganda, efektivitas volume penjualan dipengaruhi oleh strategi bauran pemasaran (Marketing Mix) yang terdiri dari: Produk, Harga, Promosi, dan Distribusi (Place).

Penelitian dari Suherman Kusniadji (2016) Alumnus Magister Ilmu Komunikasi Universitas Mercu Buana dan Dosen Fakultas Ilmu Komunikasi Universitas Tarumanagara, dengan judul "Strategi Komunikasi Pemasaran Dalam Kegiatan Pemasaran Produk Consumer Goods (Studi Kasus Pada PT Expand Berlian Mulia di Semarang)". Dengan hasil penelitian menunjukkan kesesuaian antara pola-pola konseptual yang diprediksikan berdasarkan teori-teori yang relevan dengan pola-pola temuan empirik studi kasus. Berdasarkan analisis yang dilakukan diperoleh kesimpulan yaitu strategi komunikasi pemasaran PT Expand Berlian Mulia 
menggunakan bauran promosi berupa avertising, sales, promotion, personal selling dan Marketing event. Aktivitas komunikasi pemasaran banyak didukung oleh perusahaan pemegang merek atau principal.

Dalam penelitian terdahulu diatas dengan penelitian ini terdapat beberapa perbedaan yaitu: penelitian ini tidak hanya membahas mengenai marketing mix, tetapi juga membahas mengenai promotion mix yang digunakan Cashbac.

\section{Strategi Pemasaran Komunikasi}

Menurut Kotler (2005), bauran pemasaran (Marketing mix) merupakan perangkat variabelvariabel pemasaran terkontrol yang digabungkan oleh perusahaan untuk menghasilkan tanggapan yang diinginkannya dalam pasar sasaran. Terdiri dari segala sesuatu hal yang dapat perusahaan lakukan untuk mempengaruhi permintaan akan produknya. Kemungkinankemungkinan yang banyak itu dapat dikelompokkan ke dalam 4 kelompok variabel yang dikenal dengan "4P" yaitu product, price, place, dan promotion.

1. Produk (product): adalah kombinasi barang dan jasa yang perusahaan tawarkan kepada pasar.

2. Harga (price): adalah jumlah uang yang harus dibayarkan konsumen untuk mendapatkan produk.

3. Tempat (place): menunjukkan berbagai kegiatan yang dilakukan oleh perusahaan agar produk dapat diperoleh dan tersedia bagi konsumen.

4. Promosi (promotion): adalah kegiatan-kegiatan yang dilakukan oleh perusahaan untuk mengkomunikasikan macam-macam manfaat dari produknya serta untuk meyakinkan konsumen supaya melakukan pembelian terhadap produknya.

Terdapat dua jenis media promosi yang akan digunakan dalam penelitian ini, yaitu:

1. ATL (Above the Line) memiliki target audience yang luas serta lebih menjelaskan sebuah konsep maupun ide. Komunikasi ATL tidak langsung berinteraksi dengan audiens. Media komunikasi yang digunakan meliputi televisi, majalah, koran, dan billboard.

2. BTL (Below the Line) target audience yang dimiliki cukup terbatas. Kesempatan yang diberikan oleh media maupun kegiatannya adalah untuk merasakan atau berinteraksi dan langsung membeli. Media komunikasi yang digunakan meliputi event, sponsorship, point-of-sale (POS) materials, consumer promotion, trade promotion, dan sebagainya (Meidyta, Swandi \& Hosana, 2015).

\section{Promotion Mix}

Bauran promosi (promotion mix) menurut Kotler dalam jurnal yang ditulis oleh Brenda Meidyta, Wayan Swandi \& Mendy Hosana M. (2015) memiliki 5 bauran utama, yaitu:

1. Advertising Merupakan semua penyajian non personal, promosi ide-ide, promosi prodik atau jasa yang dilakukan sponsor tertentu yang dibayar.

2. Sales promotions Berbagai insentif jangka pendek untuk mendorong keinginan mencoba atau membeli suatu produk atau jasa.

3. Public relation and publicity Berbagai program untuk mempromosikan dan/atau melindungi citra perusahaan atau produk individualnya. 
4. Personal selling Interaksi langsung dengan calon pembeli atau lebih untuk melakukan suatu presentasi, menjawab langsung dan menerima pesanan.

5. Direct Marketing Penggunaan surat, telepon, faksimil, e-mail, dan alat penghubung non personal lain untuk berkomunikasi untuk mendapatkan tanggapan langsung dari pelanggan dan calon pelanggan.

\section{METODOLOGI}

Penelitian ini menggunakan jenis penelitian kualitatif dengan pendekatan studi kasus dengan metode analisis deskriptif yang mencakup observasi, wawancara, studi dokumentasi, dan analisis data. Objek dalam penelitian ini adalah strategi pemasaran komunikasi yang dilakukan oleh tim sales dan tim Marketing di PT.Global Pay Indonesia (Cashbac). Jangka waktu penelitian yaitu dari bulan Mei 2019 sampai dengan bulan September 2019. Informan yang menjadi subjek penelitian ini adalah VP Sales, VP Marketing, GM of DM, Campaign Manager, dan Head of Perfomance. Kelima informan tersebut merupakan bagian-bagian penting yang berhubungan langsung dengan strategi marketing Cashbac serta yang menurut peneliti menjadi key person untuk penelitian kali ini.

Terdapat tiga jalur analisis data kualitatif, yiatu reduksi data, penyajian data, dan penarikan kesimpulan. Sedangkan validitas data yang digunakan yaitu triangulasi data, triangulasi teori, dan triangulasi teknik metodologis.

\section{HASIL DAN PEMBAHASAN}

PT. Global Pay Indonesia adalah perusahaan platform layanan dan pemasaran digital. Produk yang mereka miliki bernama Cashbac. Cashbac adalah perusahaan platform layanan dan pemasaran digital, sebuah aplikasi inovatif yang memungkinkan pelanggan untuk mendapatkan Cashback instan dari transaksi. Untuk bisnis, Cashbac bertindak sebagai platform pemasaran yang membantu mitra terafiliasi Cashbac untuk menjangkau pelanggan yang ditargetkan.

\section{Strategi Pemasaran Komunikasi PT. Global Pay Indonesia}

Strategi perusahaan merupakan hal yang sangat penting untuk meningkatkan penjualan bagi perusahaan. Ada beberapa strategi pemasaran yang digunakan oleh Cashbac, yaitu:

Product

Hasil dari temuan peneliti yaitu Cashbac adalah sebuah aplikasi Marketing platform yang berfungsi untuk mempromosikan merchants (nama untuk sebuah brand/merk). Selain itu, Cashbac juga merupakan reward platform. Berikut penjelasan mengenai peran aplikasi Cashbac sebagai reward platform menurut Sarah A. selaku VP Sales Cashbac:

"Cashbac itu adalah rewards platform dimana lebih banyak pengguna yang menggunakan kartu kredit. Kita tahu kalau reward diluar sana, kita hanya bisa pakai disitu-situ saja. Nah dengan adanya Cashbac, user bisa me-redeem rewards-nya disemua merchants Cashbac, user juga bisa mendapatkan Cashback rewards dari semua merchants Cashbac. Untuk reward-nya juga berbeda-beda disetiap merchants." (wawancara, 27 September 2019)

Aplikasi ini akan memberikan rewards berupa point kepada user yang membeli menggunakan aplikasi ini. Point ini dapat digunakan untuk transaksi selanjutnya disemua merchant yang telah bekerjasama. Hal inilah yang dapat ditawarkan kepasar untuk mendapatkan perhatian, 
dibeli, digunakan, atau dikonsumsi yang dapat memuaskan keinginan atau kebutuhan menurut pendapat Kotler (2009) pada jurnal yang ditulis oleh Swastha (2002).

Saat ini Cashbac sudah masuk di beberapa kategori yaitu kategori food and beverage, health and beauty, lifestyle dan shops. Cashbac yang awalnya memiliki target audience yaitu pengguna kartu kredit, sekarang sudah semakin memperluas targetnya, ke beberapa debit online sampai e-wallet.

Price

Harga (dalam hal ini adalah point) yang ditemukan dalam penelitian ini yaitu point yang ditawarkan kepada setiap pengguna diberbagai merchants pun berbeda-beda, karena harga adalah elemen termudah dalam program pemasaran yang disesuaikan (Swastha, 2002). Hal ini ditunjukkan dari:

Gambar 1. Jumlah point yang didapatkan di McDonald's

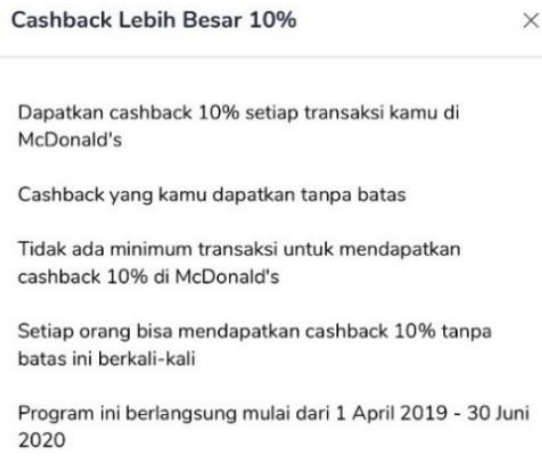

Misalnya pada gambar diatas, di McDonald's, jumlah point yang didapatkan adalah 10\% tanpa maksimal.

Gambar 2. Jumlah Point Yang Didapatkan Di Informa

Reguler Cashback $5 \%$
Dapatkan Cashback sebesar $5 \%$ dengan maksimal
cashback adalah Rp. $25.000,-$
Regular cashback $5 \%$ berlaku untuk $1 \times$ transaksi/
pengguna / hari / kartu
Kamu dapat melakukan transaksi di outlet Informa yang
terdaftar di Cashbac.

Sedangkan di Informa, point yang didapatkan yaitu sebesar 5\% dengan maskimal Rp 25.000. Perbedaan point ini juga dapat menjadi daya tarik tersendiri kepada pembeli untuk menentukan pilihan mereka saat ingin membeli menggunakan aplikasi ini. 
Place

Dari hasil temuan peneliti, Cashbac difokuskan di Jabodetabek karena target audience yang ditargetkan adalah pengguna kartu kredit. Sesuai dengan pendapat Hendri Sukotjo dan Sumanto Radix A (2010) dan Eka Umi Kalsum (2008) menyatakan bahwa variabel tempat berpengaruh secara signifikan dan positif terhadap keputusan pembelian. Tetapi karena Cashbac sudah bekerja sama dengan beberapa merchant yang nation wide, Cashbac bisa digunakan diluar Jabodetabek. Seperti yang dijelaskan oleh Sarah A. selaku VP Sales Cashbac:

"kalau untuk sekarang sience penggunanya lebih banyak credit card yang pasti kita fokuskan di Jabodetabek, tapi karena banyak nation wide merchants seperti McDonald's, Kawan Lama Group, dan lainnya. Jadi be nature, semua bisa pake Cashbac, tapi memang difokuskan di jabodetabek," (wawancara, 27 September 2019)

Sehingga Cashbac dapat dinikmati dikota-kota besar yang memiliki merchants yang telah bekerjasama dengan Cashbac.

\section{Promotion}

Dalam penelitian ini ditemukan bahwa ada beberapa macam cara yang digunakan Cashbac untuk mempromosikan produk mereka, yaitu:

\section{Advertising}

Advertising yang digunakan, yaitu Below the Line dan Above the Line. Penggunaan promosi Below the Line di Cashbac terbagi dalam beberapa hal, yaitu:

- Instagram

Saat ini Instagram Cashbac sudah memiliki 1.920 postingan dengan 21.500 followers. Didalam Instagram ini, Cashbac membagikan informasi mengenai merchants yang baru atau sudah bergabung dengan mereka, promo-promo menarik serta event yang sedang diadakan.

Gambar 3. Postingan pertama Cashbac di IG

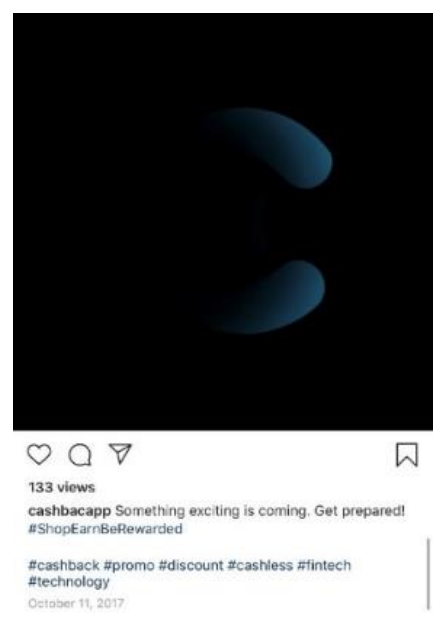

Cashbac yang didirikan pada Januari 2018, mengupload video pertama diakun Instagram @Cashbacapp pada 11 Oktober 2017 dengan caption "Something exciting is coming. Get prepared!". Cashbac mempromosikan product-nya dari sebelum dilaunching-nya product ini ke masyarakat. Video ini berhasil meraih 133 views. 
Gambar 4. Postingan Cashbac pada 30 September 2017

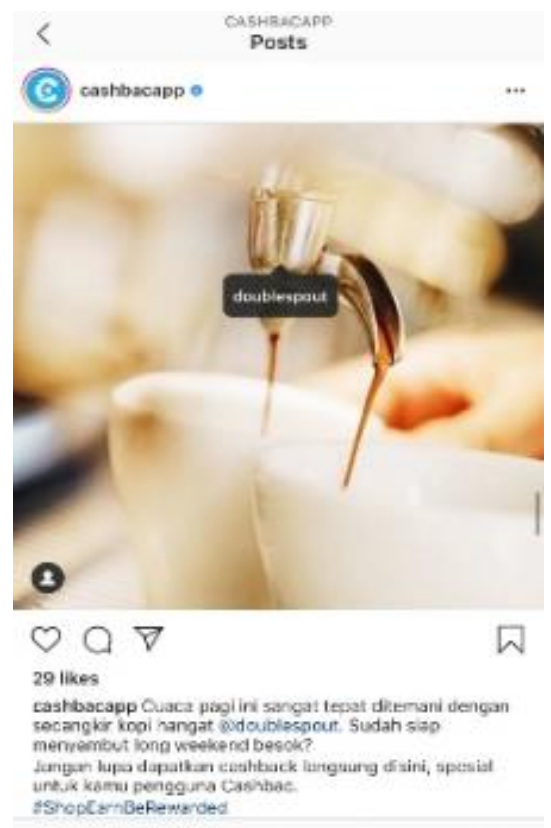

Postingan sebelum launcing-nya aplikasi ini menarik user melakukan komentar "Appnya sudah launch?" yang menandakan Cashbac berhasil membuat user menantikan aplikasinya.

Unggahan foto di Instagram Cashbac selanjutnya adalah mengenai foto produk yang menandai merchants yang mendapat kenaikan likes, yaitu diatas 20. Lalu postingan selanjutnya likes yang didapatkan semakin meningkat menjadi diatas 50 likes dan minimal satu komentar di setiap postingannya. Hingga postingan video terbaru yang diunggah Cashbac ini pada 28 September ini, mendapatkan views yaitu 1.226 views dan 12 komentar.

Instagram milik Cashbac memudahkan konsumen untuk mengetahui lebih lanjut mengenai Cashbac, promo serta merchants yang sudah bekerja sama untuk mengkomunikasikan melalui foto yang buat dengan kreatif yang menjadi menarik perhatian konsumen (Kurniawan \& Astuti, 2012).

- Youtube

Saat ini Youtube milik Cashbac sudah memiliki 355 subscriber dan 106 video. Didalam Youtube ini, Cashbac berbagi review mengenai merchants yang telah bekerjasama dengan mereka. 
Gambar 5. Video pertama di Youtube Cashbac

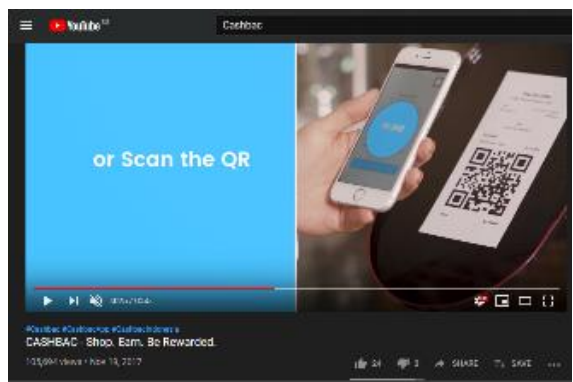

Video pertama ini menjelaskan mengenai cara pembayaran dalam aplikasi Cashbac yang diunggah pada 19 November 2017, berhasil mendapatkan 105.694 views. 5 video setelahnya, Cashbac menggunggah promo yang sedang berjalan yang mendapatkan 157-13.000 views. Setelah itu, Cashbac mereview produk yang dijual oleh merchants yang mendapatkan view 100-600 views. Tetapi untuk video "Pejuang Deadline" pada thumbnail video berhasil mendapatkan 66.000 views serta video dengan judul "Boba Hero" berhasil mendapatkan 176.000 views.

Menurut data diatas, video Cashbac lebih mendapatkan banyak respon (viewers) dari masyarakat jika diberikan judul maupun thumbnail yang berdekatan dengan kehidupan sehari-hari masyarakat karena menurut Kotler dan Keller (2016) sosial media adalah aktivitas komunikasi pemasaran yang menarik konsumen untuk meningkatkan kesadaran, citra perusahaan, dan untuk meningkatkan penjualan.

- Twitter

Saat ini Twitter Cashbac sudah memiliki 513 pengikut, dengan total postingan 1.307 tweet. Cashbac sudah bergabung di Tweeter sejak April 2017. Postingan-postingan dalam Twitter milik Cashbac berisi promo-promo yang sedang atau akan berlangsung. Keberadaan sosial media Cashbac berguna untuk memberitahu serta mengingatkan user mengenai keberadaan Cashbac app karena sosial media menjadi alat yang penting untuk melakukan pemasaran terhadap suatu produk (Kurniawan \& Astuti, 2012).

- Facebook

Cashbac memiliki 30.012 orang yang menyukai halaman Facebook-nya, serta mendapatkan 30.063 pengikut. Facebook ini digunakan untuk mempromosikan pomo-promo dan merchants yang bekerjasama dengan Cashbac. 
Gambar 6. Postingan terbaru Cashbac di Facebook

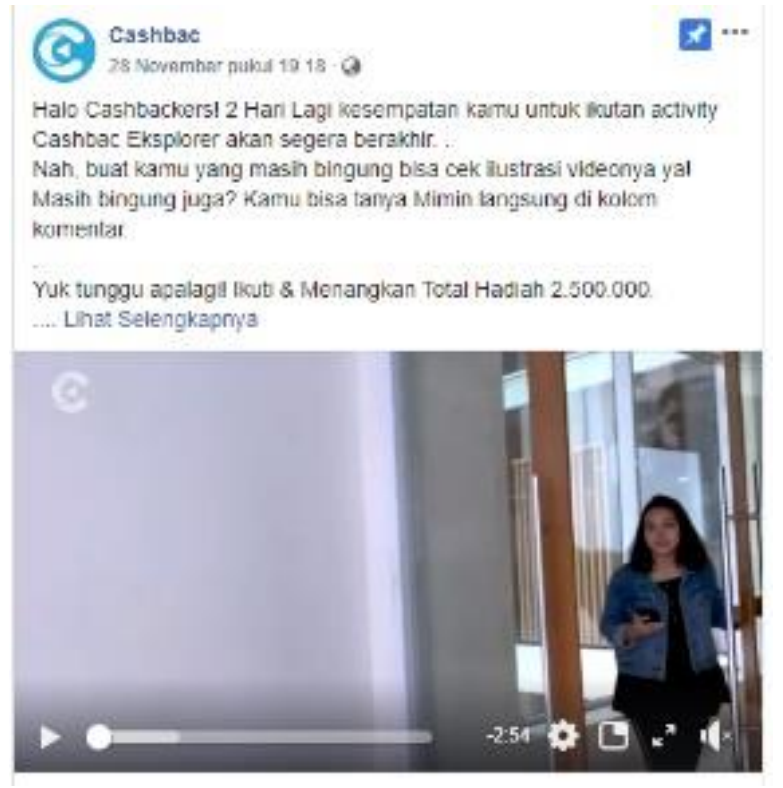

Konten satu media sosial dengan media sosial lainnya memiliki keterkaitan atau menggunggah konten yang sama terutama pada Instagram, Facebook dan Twitter dengan format yang disesuaikan dengan sosial media yang digunakan. Trusov dalam jurnal yang ditulis oleh Indika \& Jovita (2017) mengatakan bahwa WOM elektronik dan iklan melalui media sosial membantu pemasaran serta menarik konsumen dengan harga yang rendah dan lebih cepat.

- Collateral

Collateral adalah sebutan untuk banner dan tent card yang disebarkan di outlet-outlet milik merchants yang bekerjasama dengan Cashbac. Collateral yang dipasang disetiap outlet juga berbeda-beda, tergantung promo yang sedang berlangsung di outlet tersebut.

Banner-banner yang dikirimkan akan dipasang selama promo berlangsung. Meskipun collateral masuk dalam kategori BTL, collateral berperan besar dalam branding yang dilakukan Cashbac. Isi pesan dalam promosi memiliki pengaruh paling besar dalam membentuk perhatian konsumen (Silvana \& Damayanty, 2014). Semakin banyak collateral yang dipasang, masyarakat akan semakin mengenal aplikasi ini.

\section{a) Above the Line}

\section{- Google Ads}

Google ads ini terbagi menjadi dua, yaitu Google Browsing dan Google Search. Google Browsing yang dimaskud adalah saat seseorang browsing disalah satu web maupun blog, akan ditembakkan iklan Cashbac tanpa seseorang itu mencari tau mengenai Cashbac. Iklan ini berupa banner dalam bentuk gambar. Iklan ini akan tampil sesuai interest mereka. Seperti yang jelaskan oleh Randa A. selaku GM of DM Cashbac: 
"Kita beriklan di Google Search itu pada saat orang mencari Cashbac, itu kita keluarkan iklannya sehingga setiap orang mencari, itu tidak miss leading ketempat yang lain dan yang kedua itu masih di google juga, ketika orang browsing salah satu web atau blog, kita juga pasangkan banner," (wawancara, 25 September 2019)

Google Search adalah iklan yang dikeluarkan ketika user mencari mengenai Cashbac di Google Search, orang itu langsung diarahkan ke website resmi milik Cashbac supaya mendapatkan informasi yang benar dan jelas mengenai Cashbac. Website Cashbac akan muncul pada kolom paling atas dalam pencarian. Keberadaan iklan di Google ini membantu masyarakat dalam melakukan pencarian informasi mengenai Cashbac app. Sosial media disarankan kepada perusahaan yang ingin memasarkan produknya karena media sosial merupakan media pemasaran yang penting dalam menjangkau segmen pasar usia muda yang lebih cepat dan efisien (Indika \& Jovita, 2017).

- Website \& Blog

Gambar 7. Website Cashbac

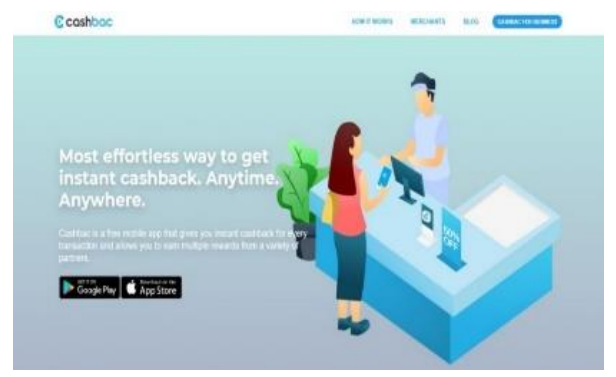

Berikut adalah tampilan depan website Cashbac dengan kolom How It Works (cara pemakaian Cashbac), kolom Merchants (daftar merchants yang telah bekerjasama dengan Cashbac), kolom Blog (informasi seputar Food and Beverage, Health and Beauty, Lifestyle, dan Shop), serta kolom Cashbac For Business (penjelasan mengenai keuntungan bergabung dengan Cashbac).

Internet adalah jaringan komputer yang menghubungkan pengguna di seluruh dunia dengan menghubungkan mereka dengan "penyimpanan informasi yang sangat besar (Kotler \& Armstrong, 2008).

- Instagram Ads

Instagram Ads atau Insta Ads adalah iklan yang dapat muncul didua tempat, yaitu di story dan postingan Instagram. Iklan yang muncul di Instagram setiap orangpun berbeda-beda, tergantung target yang diinginkan.

Adanya iklan di Insta Ads akan memudahkan masyarakat yang ingin menggunakan aplikasi Cashbac, karena bisa langsung menekan iklan yang terhubung dengan aplikasi. Pemasaran melalui sosial media memengaruhi persepsi konsumen terhadap produk dan minat beli (Indika \& Jovita, 2017).

- Facebook Ads

Facebook Ads yang digunakan Cashbac lebih mengoptimalkan promosi kepengguna baru. Seperti yang dijelaskan oleh Randa A. selaku GM of DM Cashbac: 
"Beda halnya kalau Google, Faceboook, IG, Youtube yang memang lebih komunikasi dioptimalkan ke pengguna baru".

"kalau tinggi secara install, memang dari Facebook dan IG memang masih menjadi dominasi karena penggunanya sendiri yang masih besar" (wawancara, 25 September 2019)

Beliau juga menyebutkan bahwa iklan-iklan yang disebarkan melalui Insta Ads dan juga Facebook Ads memang banyak mengundang pengguna baru untuk menginstall aplikasi Cashbac. Facebook ads sebagai media iklan online yang dipengaruhi oleh beberapa variable, misalnya frekuensi kunjungan (Utami, 2016).

- Youtube Ads

Beriklan di Youtube, menurut Randa A. selaku GM of DM Cashbac, memiliki keuntungan dalam jumlah views. Seperti yang dijelaskan oleh beliau:

"Kalau tinggi secara banyak yang melihat itu iklan di youtube, karena pengguna Youtube banyak banyak, dan kalau kita beriklan di Youtube, satu video bisa di tonton sampai satu juta view," (wawancara pada tanggal 25 September 2019)

Dalam wawancara tersebut, beliau menjelaskan bahwa iklan tertinggi yang dilihat adalah iklan yang disebarkan di Youtube. Penggunaan Youtube Ads adalah pilihan yang tepat karena iklan melalui Youtube dapat mempengaruhi minat beli (Sukamto \& Wijaksana, 2017).

\section{Personal Selling}

Personal selling yang digunakan adalah dengan membuat event digedung perkantoran yang ditargetkan dengan memperkenalkan aplikasi Cashbac dan manfaat menggunakan aplikasi tersebut. Seperti yang dijelaskan oleh Melvin G. selaku VP Marketing:

"Ada dua hal yang didapatkan oleh event, yang pertama awereness, kedua orang langsung experience. That's why kita melakukan event digedung-gedung office dulunya. Ada event di Gedung office OCBC, di Gedung Office Balpindo, dan lainnya. Kita bikin awereness sekalian edukasi, dan experience sekaligus. Tiga-tiganya dapat semua kalau kita mengadakan event." (wawancara, 30 September 2019)

Personal selling merupakan cara yang paling cepat untuk menarik pengguna jika dilakukan dilokasi yang tepat. Personal selling sangat diperlukan agar memberikan penjelasan kepada konsumen mengenai produk serta untuk mempengaruhi individu dan kelompok agar terciptanya sebuah transaksi pembelian (Kusniadji, 2018).

\section{Sales promotions}

Devisi Sales berperan sangat penting dalam meningkatkan merchants dan penjualan Sales dibagi menjadi dua bagian devisi yaitu: Aquistion dan Account Management. Aquistion adalah sales yang bertugas untuk mencari merchants untuk menawarkan kerjasama. Sedangkan Account Management (AM) memiliki tugas sebagai Merchants Relations Specialist yaitu untuk selalu berhubungan baik dengan merchants serta untuk menawarkan promo yang akan saling meningkatkan penjualan kedua belah pihak.

Usaha yang dilakukan untuk mencapai tujuan yang telah ditetapkan perusahaan salah satunya melalui kegiatan pemasaran, yaitu proses dimana perusahaan menciptakan nilai bagi pelanggan dan membangun hubungan yang kuat kepada pelanggan dengan tujuan untuk menangkap nilai dari pelanggan sebagai imbalannya (Kotler dan Amstrong, 2008). 


\section{Publicity}

Cashbac saat ini sudah melakukan publikasi dibeberapa media online, misalnya Detikinet.Com, Liputan6.Com, Tribunnews.Com, Merdeka.Com dan media-media serupa lainnya.

Gambar 8. Contoh publikasi yang telah dilakukan Cashbac

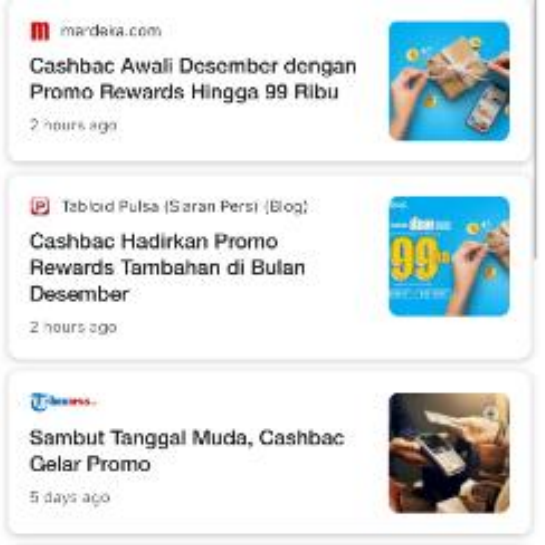

Gambar diatas merupakan contoh publikasi yang telah dilakukan Cashbac. Publikasi-publikasi ini juga dapat menarik masyarakat yang lebih luas. Penggunaan media yang paling sesuai adalah menggunakan media massa karena dapat menjangkau audiens dalam jumlah besar (Setiawan \& Farid, 2014).

\section{Direct Marketing}

Direct Marketing yang digunakan Cashbac yaitu menggunakan e-mail dan push notification. Notifikasi akan muncul jika pengguna berada berdekatan dengan merchants yang telah bekerjasama dengan Cashbac. Sedangkan E-mail yang dikirimkan kepada user bukanlah Email spam, melainkan E-mail yang sudah disesuaikan dengan behavior penggunanya. Seperti penjelasan oleh VP Marketing Cashbac, Melvin G:

"Untuk E-mail, kita lihat dari behavior user, misalnya sudah 30 hari belum kembali menggunakan Cashbac, kita kirimkan mereka merchants yang baru bekerjasama atau kita berikan promo khusus untuk mereka. hopefully mereka pake Cashbac lagi dan semakin lama mereka semakin ingat terus dengan Cashbac." (wawancara, 30 September 2019)

Hal ini tidak hanya membantu konsumen, tetapi juga merchants berada didekat pengguna, serta Cashbac. Informasi pemasaran langsung memiliki tingkat keterbacaan yang tinggi karena bahan tersebut dikirimkan pada calon pembeli (Saputra \& Wulandari, 2017).

\section{KESIMPULAN}

Dari pembahasan di atas, dapat kita simpulkan bahwa produk yang ditawarkan oleh Cashbac berbeda dengan produk lain dan menguntungkan bagi user sehingga dapat menarik daya beli konsumen. harga yang ditawarkan juga beragam, hal ini juga menjadi salah satu daya tarik konsumen untuk membantu menentukan pilihan mereka dalam membeli menggunakan Cashbac. Cashbac ditargetkan di Jabodetabek karena target sasarannya adalah pengguna kartu kredit. Cashbac menggunakan advertising BTL yaitu Instagram, Twitter, Facebook, Youtube, 
serta Collateral dan ATL yaitu Google Ads, Instagram Ads, Youtube As, Facebook Ads, Website \& Blog. Sales Promotions yang digunakan yaitu melalui tim AM dan Aquistion. Publikasi dilakukan dibeberapa media online dan offline. Personal selling yang digunakan yaitu dengan mengadakan event diperkantoran dan lokasi lainnya yang mendukung. Direct Marketing dilakukan menggunakan push notification dan e-mail. Strategi komunikasi tersebut berperan penting dalam meningkatkan penjualan Cashbac. Karena dalam penelitian ini, peneliti hanya membahas mengenai strategi komunikasi dari sisi PT. Global Pay Indonesia, akan lebih baik jika penelitian selanjutnya menggali lebih dalam mengenai strategi komunikasi yang lebih dalam lagi.

\section{DAFTAR PUSTAKA}

Indika, D. R., \& Jovita, C. (2017). Media Sosial Instagram Sebagai Sarana Promosi Untuk Meningkatkan Minat Beli Konsumen. Jurnal Bisnis Terapan, 1(01), 25. https://doi.org/10.24123/jbt.v1i01.296

Kurniawan, A. D., \& Astuti, R. T. (2012). Analisis Pengaruh Produk, Promosi, Harga Dan Tempat Terhadap Keputusan Pembelian ( Studi Pada Kedai Amarta Semarang). Diponegoro Journal of Management, 1(1), 282-289.

Kusnawan, G., \& Wijoyo P. (2008). The Influence of Marketing Mix Strategy To Effectiveness. $\operatorname{VIII}(2)$.

Kusniadji, S. (2018). Kontribusi Penggunaan Personal Selling Dalam Kegiatan Komunikasi Pemasaran Pada Era Pemasaran Masa Kini. Jurnal Komunikasi, 9(2), 176. https://doi.org/10.24912/jk.v9i2.1078

Meidyta, B., Swandi, W., M. Hosana, M., (2015) Perancangan Promosi Karoongindo Di Surabaya.

Saputra, R., \& Wulandari, A. (2017). Penerapan Direct Marketing dan Personal Selling Pada Produk Indihome ( Studi Kasus Di PT . Telekomunikasi Indonesia, Tbk . Kandatel Cijaura Bandung Pada Tahun 2017 ). E-Proceeding of Applied Science, 3(2), 528-533.

Setiawan, N. A., \& U., F. H. (2014). Strategi Promosi dalam Pengembangan Pariwisata Lokal di $\begin{array}{llll}\text { Desa Wisata Jelekong. } & \text { Trikonomika, }\end{array}$ https://doi.org/10.23969/trikonomika.v13i2.613

Silvana, H., \& Damayanty, D. (2014). Penggunaan X Banner Dalam Promosi Layanan Perpustakaan. Jurnal Kajian Komunikasi, 2(2), 105-117. https://doi.org/10.24198/jkk.vol2n2.1

Sukamto, S. M. A., \& Wijaksana, T. I. (2017). Iklan Melalui Youtube dan Minat Beli Produk. Journal of Research and Applications: Accounting and Management, 2(2), 135. https://doi.org/10.18382/jraam.v2i2.168

Swastha, B. (2002). Pengaruh Kualitas Produk Dan Harga Terhadap Keputusan Pembelian Produk Kosmetik Wardah Di Kota Bangkalan Madura. Jurnal Ekonomi , Bisnis \& Entrepreneurship, 1(1), 31-48.

Utami, W. (2016). Penetapan Advertising, Sales Promotion, Dan Direct Marketing Pada Le Magnifique. Jurnal Manajemen Dan Start-Up Bisnis, 1, 314-321. 